\title{
Deterioration Modeling of Steel Moment Resisting Frames Using Finite-Length Plastic Hinge Force-Based Beam-Column Elements
}

\author{
Filipe L. A. Ribeiro ${ }^{1}$; Andre R. Barbosa, Ph.D., M.ASCE²; Michael H. Scott, Ph.D., M.ASCE ${ }^{3}$; \\ and Luis C. Neves, Ph.D. ${ }^{4}$
}

\begin{abstract}
The use of empirically calibrated moment-rotation models that account for strength and stiffness deterioration of steel frame members is paramount in evaluating the performance of steel structures prone to collapse under seismic loading. These deterioration models are typically used as zero-length springs in a concentrated plasticity formulation; however, a calibration procedure is required when they are used to represent the moment-curvature $(M-\chi)$ behavior in distributed plasticity formulations because the resulting moment-rotation $(M-\theta)$ response depends on the element integration method. A plastic hinge integration method for using deterioration models in forcebased elements is developed and validated using flexural stiffness modifications parameters to recover the exact solution for linear problems while ensuring objective softening response. To guarantee accurate results in both the linear and nonlinear range of response, the flexural stiffness modification parameters are computed at the beginning of the analysis as a function of the user-specified plastic hinge length. With this approach, moment-rotation models that account for strength and stiffness deterioration can be applied in conjunction with force-based plastic hinge beam-column elements to support collapse prediction without increased modeling complexity. DOI: 10.1061/(ASCE)ST.1943541X.0001052. () 2014 American Society of Civil Engineers.
\end{abstract}

Author keywords: Component deterioration; Earthquake engineering; Force-based finite elements; Plastic hinge calibration; Steel; Analysis and computation.

\section{Introduction}

Performance-based seismic design and assessment requires accurate nonlinear finite element models that can capture the full range of structural response associated with various performance targets. In the development of realistic finite element models, two main aspects need to be taken into consideration. First, modes of strength and stiffness deterioration attributable to damage accumulation that could lead to local or global collapse need to be identified. Second, the models for structural components need to be reliable, robust, and computationally efficient for the entire range of the analysis. Idealized beam and column models for nonlinear structural analysis vary greatly in terms of complexity and computational efficiency, from phenomenological models, such as concentrated plasticity models

${ }^{1}$ Ph.D. Student, UNIC, Dept. of Civil Engineering, Faculdade de Ciências e Tecnologia, Universidade Nova de Lisboa, Quinta da Torre, 2829-516 Caparica, Portugal; and Visiting Ph.D. Student, School of Civil and Construction Engineering, Oregon State Univ., Corvallis, OR 97331-3212.

${ }^{2}$ Assistant Professor, School of Civil and Construction Engineering, Oregon State Univ., 220 Owen Hall, Corvallis, OR 97331-3212 (corresponding author). E-mail: andre.barbosa@oregonstate.edu

${ }^{3}$ Associate Professor, School of Civil and Construction Engineering, Oregon State Univ., 220 Owen Hall, Corvallis, OR 97331-3212.

${ }^{4}$ Lecturer, Nottingham Transport Engineering Centre, Univ. of Nottingham, Univ. Park, Nottingham NG7 2RD, U.K.; and UNIC, Dept. of Civil Engineering, Faculdade de Ciências e Tecnologia, Universidade Nova de Lisboa, Quinta da Torre, 2829-516 Caparica, Portugal.

Note. This manuscript was submitted on April 25, 2013; approved on February 11, 2014; published online on July 8, 2014. Discussion period open until December 8, 2014; separate discussions must be submitted for individual papers. This paper is part of the Journal of Structural Engineering, (C) ASCE, ISSN 0733-9445/04014112(12)/\$25.00. and distributed plasticity beam-column elements, to complex continuum models based on plane-stress or solid finite-elements.

Concentrated plasticity models (Clough et al. 1965), consist of two parallel elements, one with elastic-perfectly plastic behavior to represent yielding and the other with elastic response to represent post-yield hardening. Following the formal proposal by Giberson (1969), where nonlinear zero-length moment rotation springs are located at both ends of a linear-elastic beam-column element, this type of approach became the reference model in the development of the concentrated plasticity models. Many hysteretic laws have been proposed in the last decades accounting for the most relevant phenomena influencing member response up to collapse: cyclic deterioration in stiffness (Takeda et al. 1970) and strength (Pincheira et al. 1999; Sivaselvan and Reinhorn 2000), pinching under load reversal (Roufaiel and Meyer 1987), among many others have developed different phenomenological models that define the behavior of the concentrated plastic hinges. Even though these models were developed several years ago, they have been recently proposed as the main method for estimating seismic demands of frame structures (Ibarra and Krawinkler 2005; Medina and Krawinkler 2005; Haselton and Deierlein 2007) and have been presented as the preferred modeling approach in the ATC-72 guidelines (PEER/ATC 2010). These models allow for reliable estimation of the seismic demands in structures up to the onset of collapse with limited computational cost.

On the opposite end of the spectrum to concentrated plastic hinge $(\mathrm{CPH})$ models, continuum models are generally accepted as the most reliable approach for estimating the seismic demands of structures to localized and global collapse. However, these models are typically complex and require very time-consuming computations. Distributed plasticity finite elements offer a compromise between concentrated plasticity models and continuum finite element models. 
Three formulations for distributed plasticity elements have been proposed in the literature: force-based beam-column elements (Spacone and Filippou 1992; Neuenhofer and Filippou 1997), displacement based beam-column elements (Taylor 1977; Kang 1977), and the mixed formulation based beam-column elements (Alemdar and White 2005). Mixed formulations typically yield the best results in nonlinear structural analysis, but they have not been widely adopted in the finite element software typically employed in PBEE analyses.

Force-based beam-column elements have been shown to be advantageous over displacement-based elements for material nonlinear frame analysis (Neuenhofer and Filippou 1997; Alemdar and White 2005; Calabrese et al. 2010) by avoiding the discretization of structural members into numerous finite elements, thereby reducing the number of model degrees of freedom. In these formulations, the behavior of a section is described by a fiber model or a stress resultant plasticity model (El-Tawil and Deierlein 1998).

Despite these advantages, localization issues related to nonobjective strain-softening response (Coleman and Spacone 2001) led to the development of force-based finite-length plastic hinge beamcolumn elements (FLPH elements in short) by Scott and Fenves (2006) and Addessi and Ciampi (2007). Conceptually, these elements are composed of two discrete plastic hinges and a linear elastic region, all of which are incorporated in the element integration method. Through the selection of experimentally calibrated plastic hinge lengths and appropriate definition of the integration scheme, localization can be avoided. The main advantages of the FLPH elements are: (1) the explicit definition of the plastic hinge length, which allows for the recovery of meaningful local cross-section results (e.g., curvatures and bending moments); (2) a clear distinction between beam-column inelasticity from the nonlinear behavior of connections; and (3) a reduced number of nodes, elements and degrees of freedom. These advantages motivate the search for alternate calibration approaches as presented in this paper. Although, these elements have been used successfully in simulating the seismic response of structures (Berry et al. 2008), they require the definition of a moment-curvature relationship and plastic hinge length to represent a desired moment-rotation behavior.

Based on a large database of experimental results, Lignos and Krawinkler (2011) have developed and validated multilinear moment-rotation relationships that can be used to capture plastic hinge behavior in simulating the deteriorating response of steel structures to collapse. Other authors have reported similar moment-rotation relationships for reinforced concrete structures (Haselton and Deierlein 2007) and load-displacement relationships for timber structures (Foliente 1995), which account for other modes of deterioration not typically observed in steel structures. The developed moment-rotation $(M-\theta)$ relationships can be used directly in $\mathrm{CPH}$ elements following approaches presented in Ibarra and Krawinkler (2005). However, several other beam-column elements formulations, such as the FLPH elements, require the definition of moment-curvature relationships in the plastic hinge regions. For example, for the modified Gauss-Radau integration scheme (Scott and Fenves 2006), where the end points weights are equal to the plastic hinge length $L_{p}$, moment-curvature relationships are required for the two end sections. The direct scaling of the moment-rotation relationship by the plastic length $L_{p}$ to obtain a moment-curvature $(M-\chi)$ relationship [i.e., by dividing each rotation by $L_{p}\left(\chi_{i}=\theta_{i} / L_{p}\right)$ ], at first may seem a logical approach. However, this leads to erroneous results when no further calibration is performed, as shown by Scott and Ryan (2013) for the common case of elasto-plastic behavior with linear strain hardening under antisymmetric bending.
The objective of this paper is to present a plastic-hinge calibration approach that allows for simulation of structures using FLPH elements that use the modified Gauss-Radau integration scheme and make use of recent multilinear moment-rotation constitutive laws that have been derived from experimental results. This calibration procedure can be implemented in a finite element framework, decreasing the user's modeling effort, while providing accurate and reliable results.

The calibration procedure includes the definition of section flexural stiffness modification parameters at the beginning of the nonlinear structural analysis. These modification parameters are computed as a function of the plastic hinge to span length ratio by comparison of the element flexibility and the target flexibility.

The proposed calibration methodology improves the quality and reliability of the results obtained without a notable increase either in computation cost or in the complexity of structural model. Nonetheless, it is worth noting that the influence of other effects that are typically considered in two-dimensional (2D) frame modeling of built infrastructure still need to be taken into account. Examples of relevant effects are slab stiffness and strength deterioration on cyclic performance of beams, diaphragm action, load distribution, and mathematical representation of damping, among others (Gupta and Krawinkler 1999). The validation of the calibration approach is performed for nonlinear static (pushover) analyses. However, for full implementation in finite element software, nonlinear cyclic static and dynamic analyses including strength and stiffness deterioration are needed in the future, as these cases fall outside the scope of this paper. In addition, the proposed calibration scheme was only developed for the modified Gauss-Radau scheme, as it is found to be advantageous over other methods, namely by avoiding localization issues, in the analysis of structures to seismic loading and is implemented in a FLPH element (Scott and Fenves 2006). The application of the calibration approach to other integration methods falls outside the scope of this work.

\section{Problem Statement}

\section{Empirical Steel Component Deterioration Moment-Rotation Behavior}

To simulate component deterioration, Ibarra and Krawinkler (2005) proposed a phenomenological model to simulate the deterioration of steel elements, which Lignos and Krawinkler (2011) adapted to define deteriorating moment-rotation relationships for plastic hinges in steel elements using data from a large set of experimental tests. The hysteretic behavior of the steel components is based on the force-displacement envelope (backbone curve) illustrated in Fig. 1. Although steel structures are often modeled considering elasto-plastic constitutive behavior with linear strain hardening, during a severe ground motion, significant inelastic cyclic deformations cause deterioration of elements, reducing their strength and stiffness. This deterioration is significant in the analysis of steel structures under cyclic lateral loads as it influences not only the resistance of the structure, but also its stiffness and its resulting dynamic behavior. The backbone curve for the adopted momentrotation model $(M-\theta)$ is defined in terms of: (1) yield strength and rotation $\left(M_{y}\right.$ and $\left.\theta_{y}\right) ;(2)$ capping strength and associated rotation for monotonic loading $\left(M_{c}\right.$ and $\left.\theta_{c}\right) ;(3)$ plastic rotation for monotonic loading $\left(\theta_{p}\right) ;(4)$ post-capping rotation $\left(\theta_{p c}\right) ;(5)$ residual strength $M_{r}=\kappa \times M_{y}$; and (6) ultimate rotation $\left(\theta_{u}\right)$. Other model parameters permit the definition of cyclic strength, post-capping strength, accelerated reloading stiffness and unloading stiffness deterioration (Lignos and Krawinkler 2013). 


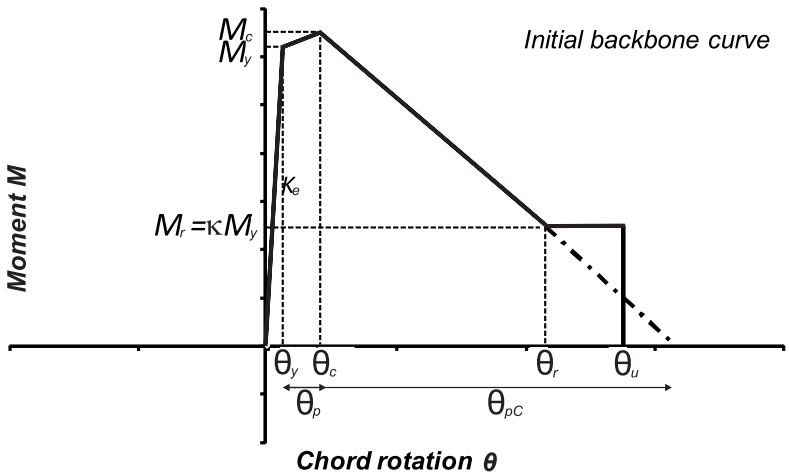

(a)

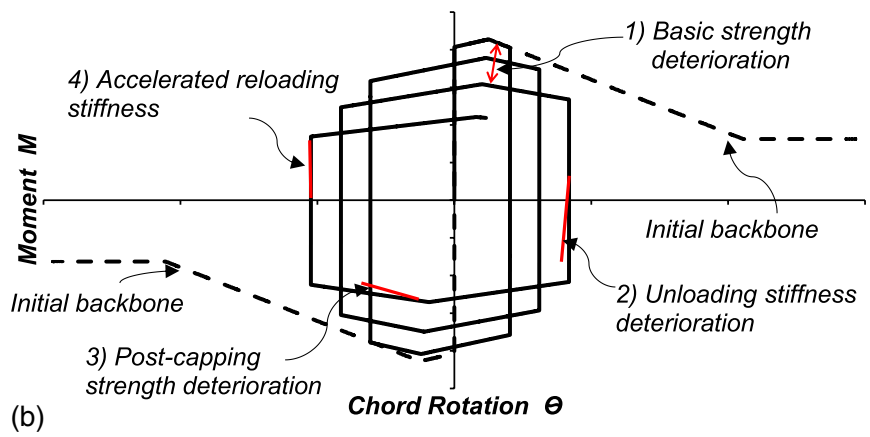

Fig. 1. Adapted modified Ibarra-Krawinkler model: (a) backbone curve; (b) basic modes of cyclic deterioration

\section{CPH Models}

The empirical models described above can be used directly in the zero-length moment-rotation springs of $\mathrm{CPH}$ elements. In the case of double curvature or antisymmetric bending, which is the reference case for the empirical moment-rotation models used in Ibarra and Krawinkler (2005) and in Lignos and Krawinkler (2011), the global element initial flexural stiffness of the one component $\mathrm{CPH}$ becomes $6 E I / L$, where $E I$ is the cross-section flexural stiffness, and $L$ is the element length. The flexibilities of the zero-length moment-rotation springs and the element interior are additive, giving the total element flexibility

$$
\mathbf{f}=\mathbf{f}_{I}+\mathbf{f}_{\mathrm{int}}+\mathbf{f}_{J}
$$

where $\mathbf{f}_{\text {int }}$ is the flexibility of the linear-elastic element interior, and $\mathbf{f}_{I}$ and $\mathbf{f}_{J}$ are the flexibilities of the springs at ends $I$ and $J$, respectively.

The correct linear-elastic solution for the entire element is only obtained if the end rotational springs are approximated as rigidplastic. Thus, linear elastic cross-section stiffness of the springs at both ends are affected by a constant $n$ (typically greater than 10) such that the initial stiffness of the springs is large, but not so large as to pose numerical instability, as shown in Appendix I. Because the elastic stiffness of the member is related to the elastic stiffness of the rotational springs and the beam-column element, which are connected in series, the stiffness of the element interior is also affected by $n$, and is expressed as

$$
E I_{\mathrm{mod}}=E I \frac{n+1}{n}
$$

which translates to spring initial stiffness given by

$$
k_{m}=n \frac{6 E I_{\mathrm{mod}}}{L}, \quad m=I, J
$$

Following the methodology in Ibarra and Krawinkler (2005), the ratio of post-yield to elastic stiffness of the spring, $\alpha^{\prime}$ (ratio of the tangent stiffness, $k_{T m}$, to the linear elastic stiffness, $k_{m}$ ) is given by

$$
\alpha^{\prime}=\frac{k_{T m}}{k_{m}}=\frac{\alpha}{1+n \times(1-\alpha)}
$$

where $\alpha$ is the nominal post-yielding to elastic stiffness ratio, and $\alpha^{\prime}$ is assigned to the end springs in the $\mathrm{CPH}$ model to reproduce the correct moment-rotation behavior of the member. The ratio $\alpha^{\prime}$ is thus defined such that the correct nonlinear moment-rotation stiffness of the member, defined as $\alpha \times 6 E I / L$, is recovered.

\section{Finite-Length Plastic Hinge Elements}

The FLPH element developed by Scott and Fenves (2006) is based on the force-based beam-column finite element formulation by Spacone et al. (1996) and uses alternative numerical integration schemes to account for user-defined plastic hinge lengths. The force-based beam-column finite element is formulated assuming small displacements in a simply-supported basic system free of rigid-body displacements. Fig. 2 illustrates the basic system in which the vector of element-end forces, $\mathbf{q}$, the vector of element deformations, $\mathbf{v}$, the internal section forces, $\mathbf{s}(x)$, and section deformations, $\mathbf{e}(x)$, are shown for a $2 \mathrm{D}$ element. Section forces correspond to the axial force and bending moments, whereas the section deformations correspond to axial strain and curvature.

Equilibrium between the section forces $\mathbf{s}(x)$ at a location $x$, and basic element forces $\mathbf{q}$ is given by

$$
\mathbf{s}(x)=\mathbf{b}(x) \mathbf{q}+\mathbf{s}_{\mathbf{0}}(x)
$$

where $\mathbf{b}(x)$ is the interpolation function matrix, and $\mathbf{s}_{\mathbf{0}}(x)$ corresponds to a particular solution associated with element loads. Eq. (5) can be expanded into different forms depending on the number of dimensions of the problem and the beam theory selected. For the 2D Euler-Bernoulli beam-column element, the basic forces are $\mathbf{q}=\left\{q_{1}, q_{2}, q_{3}\right\}^{T}$ and the section forces are $\mathbf{s}(x)=\{N(x), M(x)\}^{T}$, all of which are shown in Fig. 2. Compatibility between element deformations $\mathbf{v}$ and section deformations $\mathbf{e}$ is expressed as

$$
\mathbf{v}=\int_{0}^{L} \mathbf{b}(x)^{T} \mathbf{e}(x) d x
$$

The element flexibility matrix is obtained through linearization of the element deformations $\mathbf{v}$ with respect to basic forces $\mathbf{q}$ and is given by

$$
\mathbf{f}=\frac{\partial \mathbf{v}}{\partial \mathbf{q}}=\int_{0}^{L} \mathbf{b}(x)^{T} \mathbf{f}_{S}(x) \mathbf{b}(x) d x
$$

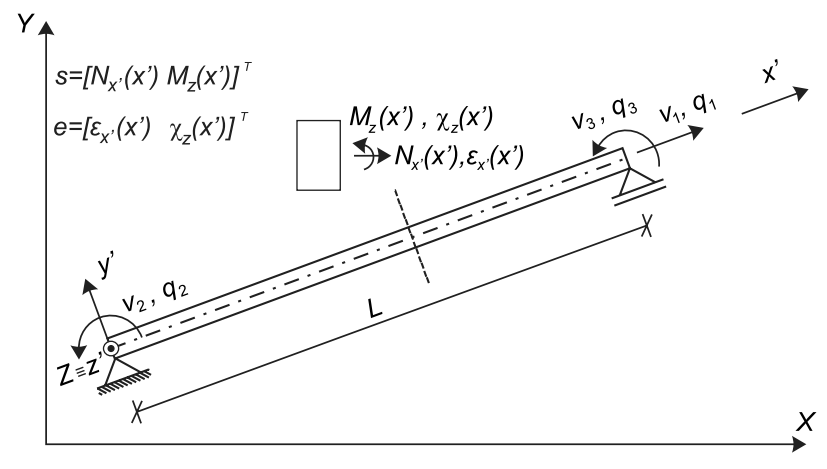

Fig. 2. Basic system for two-dimensional frame elements 
where $\mathbf{f}_{S}$ is the section flexibility, equal to the inverse of the section stiffness $\mathbf{f}_{S}=\mathbf{k}_{S}^{-1}$. The section stiffness is obtained from linearization of the constitutive relationship between section forces and section deformations, $\mathbf{k}_{S}=\partial \mathbf{s} / \partial \mathbf{e}$, at the current element state. The implementation details of the force-based element formulation into a displacement-based software were presented by Neuenhofer and Filippou (1997) and are not reproduced here for brevity.

Numerical evaluation of Eq. (6) is given by

$$
\mathbf{v}=\sum_{i=1}^{N_{P}}\left(\left.\mathbf{b}^{T} \mathbf{e}\right|_{x=\xi_{i}}\right) w_{i}
$$

where $N_{P}$ is the number of integration points over the element length, and $\xi_{i}$ and $w_{i}$ are the associated locations and weights. The element flexibility is therefore given by

$$
f=\sum_{i=1}^{N_{P}}\left(\left.b^{T} f_{S} b\right|_{x=\xi_{i}}\right) w_{i}
$$

The main issue related to use of this formulation is the localization of strain and displacement responses that can be obtained in the case of strain-softening response of force-based distributed plasticity elements (Coleman and Spacone 2001). Scott and Fenves (2006) and Addessi and Ciampi (2007) proposed methods for force-based FLPH integration, where the element is divided in three segments, two corresponding to the plastic hinges at both ends, with length $L_{p I}$ and $L_{p J}$, and a linear segment connecting both hinges [Fig. 3(a)]. Thus, Eq. (6) simplifies to

$$
\begin{aligned}
\mathbf{v}= & \int_{0}^{L_{p I}} \mathbf{b}(x)^{T} \mathbf{e}(x) d x+\int_{L_{p I}}^{L-L_{p J}} \mathbf{b}(x)^{T} \mathbf{e}(x) d x \\
& +\int_{L-L_{p J}}^{L} \mathbf{b}(x)^{T} \mathbf{e}(x) d x
\end{aligned}
$$

Various approaches were proposed by Scott and Fenves (2006) and Addessi and Ciampi (2007) to evaluate this integral numerically; however, the focus herein is the modified Gauss-Radau integration scheme which retains the correct linear elastic solution while using the specified plastic hinge lengths as the integration weights at the element ends.

In this method both end sections are assigned a nonlinear behavior, whereas the element interior is typically assumed to have an elastic behavior, although this assumption is not necessary. The flexibility of the FLPH element can be computed as

$$
\begin{aligned}
\mathbf{f}= & \int_{L_{p I}} \mathbf{b}(x)^{T} \mathbf{f}_{S}(x) \mathbf{b}(x) d x+\int_{L_{\mathrm{int}}} \mathbf{b}(x)^{T} \mathbf{f}_{S}(x) \mathbf{b}(x) d x \\
& +\int_{L_{p J}} \mathbf{b}(x)^{T} \mathbf{f}_{S}(x) \mathbf{b}(x) d x
\end{aligned}
$$

where $L_{\text {int }}$ is the length of the linear-elastic element interior.

Using the modified Gauss-Radau integration scheme for the plastic hinge regions, Eq. (11) can be rewritten as

$$
\begin{aligned}
\mathbf{f}= & \sum_{i=1}^{N_{p I}}\left(\left.\mathbf{b}^{T} \mathbf{f}_{s} \mathbf{b}\right|_{x=\xi_{i}}\right) w_{i}+\int_{L_{\mathrm{int}}} \mathbf{b}(x)^{T} \mathbf{f}_{S}(x) \mathbf{b}(x) d x \\
& +\sum_{i=N_{p I}+1}^{N_{p I}+N_{p J}}\left(\left.\mathbf{b}^{T} \mathbf{f}_{s} \mathbf{b}\right|_{x=\xi_{i}}\right) w_{i}
\end{aligned}
$$

where $N_{p I}$ and $N_{p J}$ are the number of integration points associated with the plastic hinges at the element ends. For the modified
Gauss-Radau integration $N_{p I}=N_{p J}=2$. The element interior term can be computed exactly when the element interior is elastic and there are no member loads. Nonetheless, the element interior can also be analyzed numerically. In this case, the Gauss-Legendre integration scheme is appropriate to integrate the element interior. If two integration points are placed in this region, a total of six integration points are defined along the element length. The location $\xi_{i}$ of the integration points associated with the modified Gauss-Radau plastic hinge integration, represented in Fig. 3(a), are given by

$$
\xi=\left\{\xi_{\mathbf{I}}, \xi_{\text {int }}, \xi_{\mathbf{J}}\right\}
$$

where

$$
\begin{aligned}
& \xi_{\mathbf{I}}=\left\{0 ; \frac{8 L_{p I}}{3}\right\} \\
& \xi_{\text {int }}=\left\{4 L_{p}+\frac{L_{\text {int }}}{2} \times\left(1-\frac{1}{\sqrt{3}}\right) ; 4 L_{p}+\frac{L_{\text {int }}}{2} \times\left(1+\frac{1}{\sqrt{3}}\right)\right\} \\
& \xi_{\mathbf{J}}=\left\{L-\frac{8 L_{p J}}{3} ; L\right\}
\end{aligned}
$$

The corresponding weights $w_{i}$ are given by

$$
\mathbf{w}=\left\{\mathbf{w}_{\mathbf{I}}, \mathbf{w}_{\text {int }}, \mathbf{w}_{\mathbf{J}}\right\}
$$

where

$$
\begin{aligned}
& \mathbf{w}_{\mathbf{I}}=\left\{L_{p I} ; 3 L_{p I}\right\} \\
& \mathbf{w}_{\mathbf{J}}=\left\{3 L_{p J} ; L_{p J}\right\}
\end{aligned} \quad \mathbf{w}_{\text {int }}=\left\{\frac{L_{\text {int }}}{2} ; \frac{L_{\text {int }}}{2}\right\}
$$

In this case, the element flexibility is then given by

$$
\mathbf{f}=\sum_{i=1}^{6}\left(\left.\mathbf{b}^{T} \mathbf{f}_{s} \mathbf{b}\right|_{x=\xi_{i}}\right) w_{i}
$$

where this equation is consistent with points and weights shown in Fig. 3(a).

\section{Calibration of Force-Based Finite-Length Plastic Hinge Elements}

The FLPH formulation requires the definition of moment-curvature relationships in the plastic hinge region, and subsequent procedures to relate these relationships to the moment-rotation response of the element. In this section, a novel method for calibration of the moment-rotation behavior of finite-length plastic hinge force-based frame elements is proposed for arbitrary plastic hinge lengths. With this approach, moment-rotation models that account for strength and stiffness deterioration can be applied in conjunction with FLPH models to support collapse prediction of frame structures. The approach includes an automatic calibration procedure embedded in the numerical integration of the element, freeing the analyst of this task. The calibration procedure is formulated for the modified Gauss-Radau integration scheme. However, it can be applied to other plastic hinge methods proposed by Scott and Fenves (2006) and Addessi and Ciampi (2007), function of the weight and location of the integration points used in the calibration.

The main goals of this calibration procedure are to:

1. Use empirical moment-rotation relationships that account for strength and stiffness deterioration to model the flexural behavior of the plastic hinge region;

2. Guarantee that the flexural stiffness is recovered for the nominal prismatic element during the entire analysis; and 

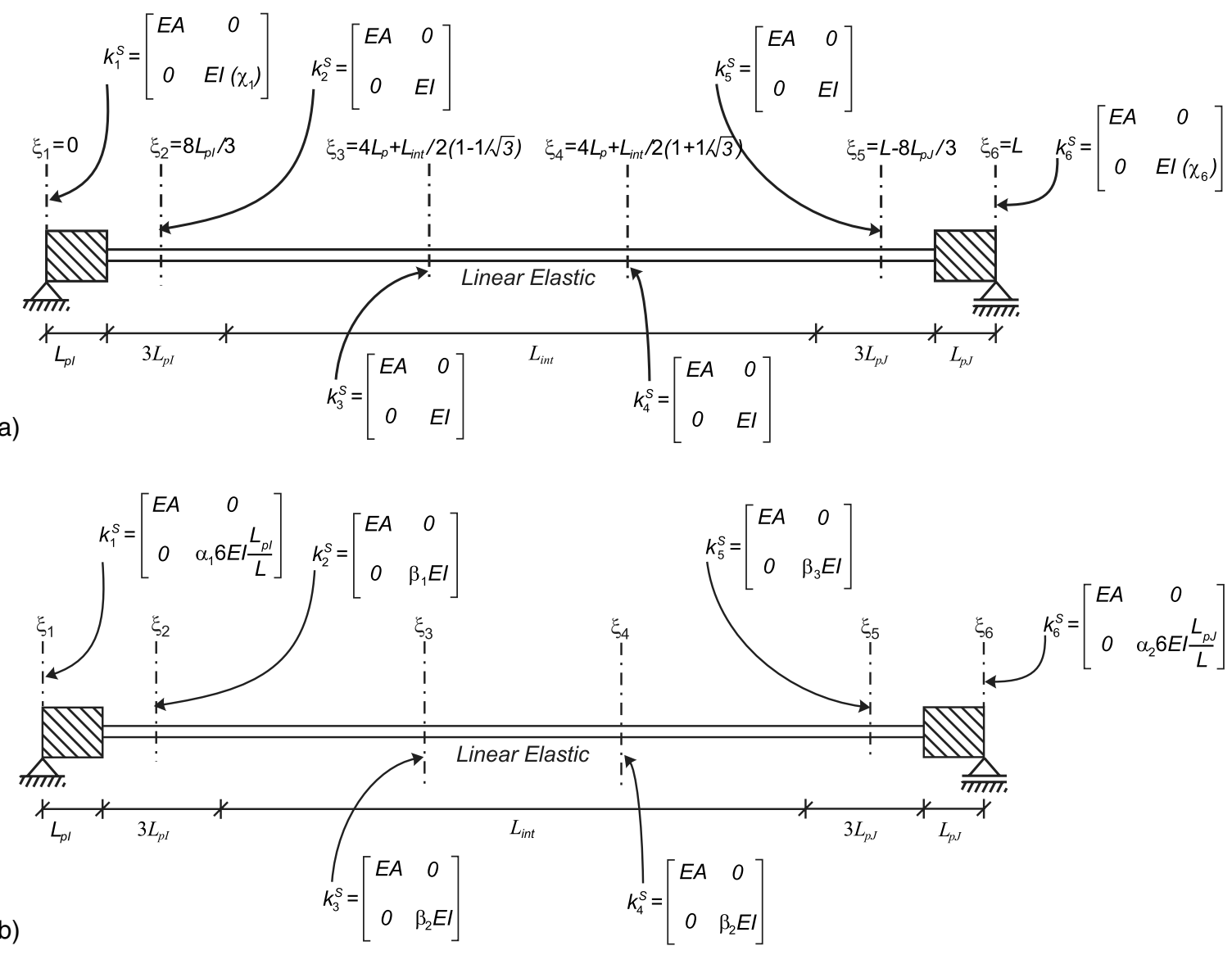

Fig. 3. Modified Gauss-Radau integration scheme for (a) original formulation as per Scott and Fenves (2006); (b) the formulation proposed in this paper

3. Allow the definition of arbitrary plastic hinge lengths by the analyst.

The presented calibration procedure is performed at the element level through the introduction of section flexural stiffness modification parameters at internal sections of the beam-column element making it possible to scale a moment-rotation relation to obtain moment-curvature relations for the plastic hinge regions. Defining the moment-rotation stiffness of the plastic hinge regions as

$$
k_{M-\theta}=\frac{\alpha 6 E I}{L}
$$

and making use of a user-defined plastic hinge length at either end of the element ( $L_{p I}$ and $L_{p J}$ for ends $I$ and $J$, respectively), the moment-curvature relations can be defined as

$$
k_{M-\chi}=\frac{\alpha 6 E I}{L} \times L_{P\{I, J\}}
$$

As highlighted by Scott and Ryan (2013), the moment-rotation and moment-curvature relations are identical for $L_{P\{I, J\}} / L=1 / 6$. However, for any other plastic hinge length, the definition of the moment-curvature through direct scaling of the moment-rotation given by Eq. (19) yields incorrect section stiffness, which in turn leads to incorrect member stiffness. The calibration procedure presented herein compensates for the incorrect stiffness of the plastic hinge moment-curvature relationship by modifying the flexural stiffness of each of the four internal sections [integration points $\xi_{2}$, $\xi_{3}, \xi_{4}$ and $\xi_{5}$ in Fig. 3(a)], assumed to remain linear elastic throughout the analysis, using one of three different parameters, $\beta_{1}, \beta_{2}$, and $\beta_{3}$, shown in Fig. 3(b).

The $\beta$ modification parameters are quantified such that the element flexibility matrix is: (1) within the elastic region, equal to the analytical solution for an elastic prismatic element; and (2) after yielding, identical to the target flexibility, i.e., is similar to the user-defined $M-\theta$ behavior. The target flexibility matrix in the elastic and nonlinear regions can be provided by the $\mathrm{CPH}$ model using Eqs. (1)-(4). Then, the modification parameters are defined based on the equivalence of the flexibility matrices associated with the CPH and FLPH models. The target flexibility can be computed using different models and herein the models defined by Lignos and Krawinkler (2011) are used in the derivations. In the calibration procedure, double curvature or anti-symmetric bending is assumed to obtain the elastic stiffness of the structural element. This is a common result of the lateral loading and boundary conditions considered in seismic analysis of frame structures. In this case, the elastic element $M-\theta$ stiffness is $6 E I / L$. However, the calibration procedure shown herein is valid for any element moment-rotation stiffness and moment gradient.

\section{Derivation of Modification Parameters}

For the 2D beam-column element, a system of three integral equations corresponding to each of the unique flexural coefficients of the element flexibility matrix is constructed. The flexibility matrix coefficients obtained from Eq. (17), corresponding to the FLPH, are equated to the flexibility matrix coefficients obtained 
from Eq. (1), associated with a $\mathrm{CPH}$ model and the empirical model. From this system of equations, the three elastic stiffness modification parameters, $\beta_{1}, \beta_{2}$, and $\beta_{3}$, can be computed as a function of $L_{p I}, L_{p J}, L$, and $n$, which is the elastic stiffness modification parameter of the $\mathrm{CPH}$ model. The code for solving the system of equations, which is implemented in the wxMaxima software (Souza et al. 2003) and is presented in the Appendix II. When $n$ tends to infinity, $\beta_{1}, \beta_{2}$, and $\beta_{3}$ are given by

$$
\begin{aligned}
& \beta_{1}=-\frac{54 L_{p I} L^{3}-6 L_{p I}\left(60 L_{p I}+60 L_{p J}\right) L^{2}+6 L_{p I}\left(96 L_{p I}^{2}+288 L_{p I} L_{p J}+96 L_{p J}^{2}\right) L-6 L_{p I}\left(256 L_{p I}^{2} L_{p J}+256 L_{p I} L_{p J}^{2}\right)}{L\left(3 L-16 L_{p J}\right)\left(L^{2}-20 L L_{p I}+4 L_{p J} L+64 L_{p I}^{2}\right)} \\
& \beta_{2}=-\frac{3\left(4 L_{p I}-L+4 L_{p J}\right)\left(3 L^{2}-12 L L_{p I}-12 L L_{p J}+32 L_{p I} L_{p J}\right)}{L\left(3 L-16 L_{p I}\right)\left(3 L-16 L_{p J}\right)} \\
& \beta_{3}=-\frac{54 L_{p J} L^{3}-6 L_{p J}\left(60 L_{p I}+60 L_{p J}\right) L^{2}+6 L_{p J}\left(96 L_{p I}^{2}+288 L_{p I} L_{p J}+96 L_{p J}^{2}\right) L-6 L_{p J}\left(256 L_{p I}^{2} L_{p J}+256 L_{p I} L_{p J}^{2}\right)}{L\left(3 L-16 L_{p I}\right)\left(L^{2}-20 L L_{p J}+4 L_{p I} L+64 L_{p J}^{2}\right)}
\end{aligned}
$$

If both plastic hinges have the same length, i.e., $L_{p}=$ $L_{p I}=L_{p J}$, Eq. (20) simplifies significantly to

$$
\begin{aligned}
& \beta_{1}=\beta_{3}=-\frac{6\left(3 L^{2} L_{p}-24 L L_{p}^{2}+32 L_{p}^{3}\right)}{L\left(L-8 L_{p}\right)^{2}} \\
& \beta_{2}=\frac{3\left(3 L^{3}-48 L^{2} L_{p}+224 L L_{p}^{2}-256 L_{p}^{3}\right)}{L\left(3 L-16 L_{p}\right)^{2}}
\end{aligned}
$$

It is worth noting that in Eq. (21) there are singularities in $\beta_{1}$ and $\beta_{3}$ for $L_{p} / L=1 / 8$ and in $\beta_{2}$ for $L_{p} / L=3 / 16$, which correspond to cases in which: (1) the length of the elastic element interior, $L_{\text {int }}$, is equal to zero; and (2) the two internal integration points $\xi_{2}$ and $\xi_{5}$ shown in Fig. 3(b) are colocated.

In Fig. 4 the flexural stiffness modification parameters of Eq. (21) are represented as a function of the plastic hinge length to span ratio $L_{p} / L$. Both parameters $\beta_{1}$ and $\beta_{3}$ are equal for all $L_{p} / L$ ratios, as both plastic hinges have the same flexural stiffness $\alpha_{1} 6 E I L_{p} / L=\alpha_{2} 6 E I L_{p} / L$. Note that the calibration procedure is valid when $L_{\text {int }}<0$, i.e., $L_{p} / L>1 / 8$.

The proposed calibration procedure is illustrated in Fig. 5 for the specific case of a nonlinear static (pushover) analysis. The pushover analysis is conducted by controlling a $j$ th degree of freedom (DOF). Furthermore, the displacement $U_{f}$ and pseudo-time $\lambda$ are initialized to zero, and the displacement increment $d U_{f}$ for the control DOF and the reference load pattern $P_{\text {ref }}$ are also initialized. The stiffness matrix $K_{f}$ is computed in the form stiffness matrix procedure (Fig. 6) at the beginning of each analysis step and each Newton-Raphson (NR) iteration. In this procedure, the parameters $\alpha_{1}$ and $\alpha_{2}$ are calculated based on the committed (converged in a previous step) element forces and deformations, and the tangent stiffness. In the first analysis step, the section stiffness modification parameters $\beta_{1}, \beta_{2}$, and $\beta_{3}$ are computed, as shown in Fig. 6. Once the stiffness modification parameters are computed, the stiffness matrix is computed through inversion of the flexibility matrix. The stiffness matrix is obtained considering the integration points (IPs) of the modified Gauss-Radau integration scheme shown in Fig. 3(b). Transformation from the basic to the local coordinate system is performed with the matrix $A_{f}$. From this point onward a traditional NR algorithm is used, repeating the above procedure at the beginning of each analysis step and at each NR iteration. Different strategies can be used in updating the model state determination, namely: (1) update state of the model domain (displacements, pseudo-time, forces) using the residual tangent displacement from the previous iteration; (2) decrease the displacement increment and update the model domain trying to overcome convergence problems; (3) change the numerical method used (either for this analysis step only or for all remaining steps);

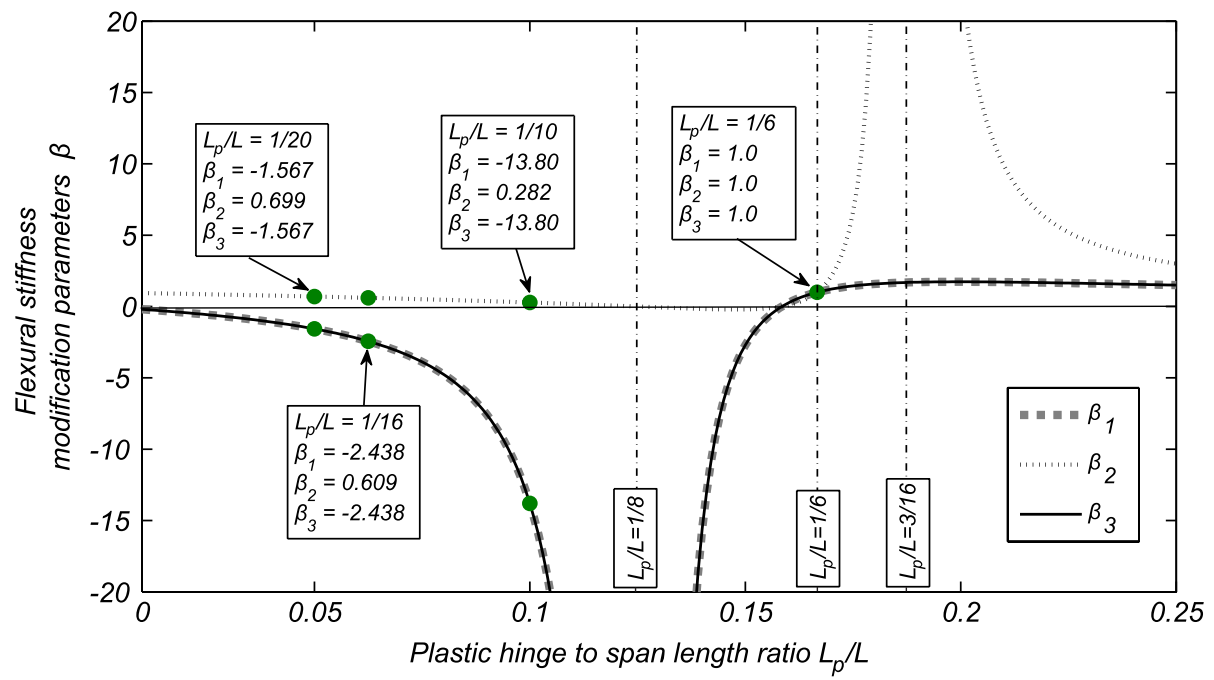

Fig. 4. Flexural stiffness modification parameters $\beta_{1}, \beta_{2}$ and $\beta_{3}$ as a function of the plastic hinge length to span ratio $L_{p} / L$ 


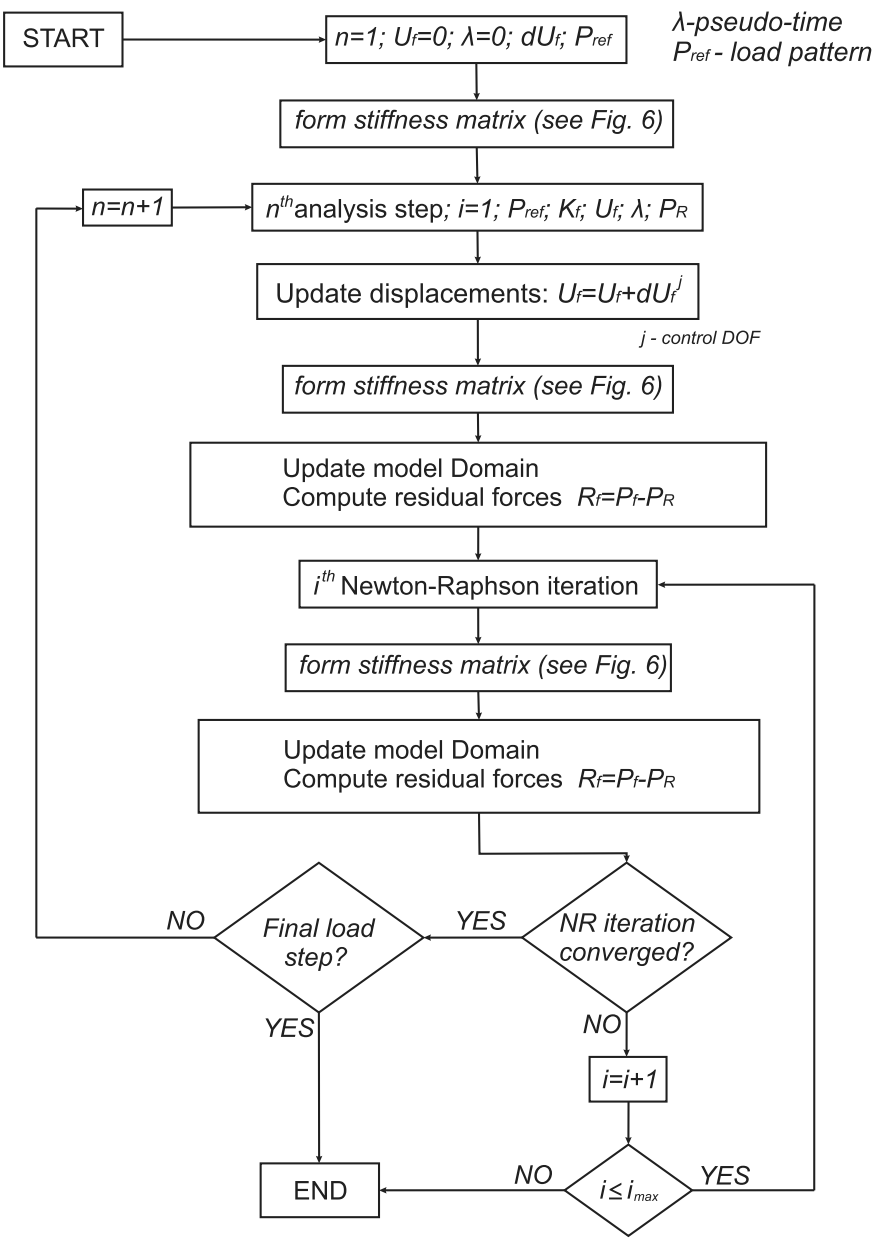

Fig. 5. Calibration procedure for a nonlinear static structural (pushover) analysis

and (4) change the tolerance criteria (if that is admissible for the case being analyzed). In case the NR method is not able to converge after a user-defined maximum number of iterations, $i_{\max }$, the analysis is stopped, and is considered not to have converged. Illustrative examples are presented in the following sections. Different solution algorithms may be used to solve the nonlinear
Table 1. Element Properties for Numerical Examples

\begin{tabular}{|c|c|c|c|c|c|c|}
\hline \multirow[b]{2}{*}{$\begin{array}{l}\text { Application } \\
\text { examples }\end{array}$} & \multicolumn{2}{|c|}{$\begin{array}{l}\text { Geometric } \\
\text { parameters }\end{array}$} & \multicolumn{4}{|c|}{$\begin{array}{l}\text { Moment-rotation } \\
\text { model parameters }\end{array}$} \\
\hline & $\begin{array}{c}\text { Inertia } \\
\left(\mathrm{m}^{4}\right)\end{array}$ & $\begin{array}{l}\text { Area } \\
\left(\mathrm{m}^{2}\right)\end{array}$ & $\begin{array}{c}M_{y} \\
(\mathrm{kNm})\end{array}$ & $M_{c} / M_{y}$ & $\begin{array}{c}\theta_{p} \\
(\mathrm{rad})\end{array}$ & $\begin{array}{r}\theta_{p c} \\
(\mathrm{rad})\end{array}$ \\
\hline Examples 1 and 2 & 0.0002 & 0.0073 & 320.78 & 1.05 & 0.0692 & 0.168 \\
\hline Frame beams & 0.0111 & 0.0551 & $1,911.0$ & 1.05 & 0.025 & 0.25 \\
\hline Frame columns & 0.0111 & 0.0551 & 969.0 & 1.05 & 0.03 & 0.35 \\
\hline
\end{tabular}

residual equations (De Borst et al. 2012; Scott and Fenves 2010). The NR algorithm is one of the most widely used and is a robust method for solving nonlinear algebraic equations of equilibrium. In this figure (Fig. 5) the flowchart for the calibration procedure is exemplified using the NR algorithm.

\section{Numerical Examples}

The proposed methodology was applied to a set of simply supported beams subjected to end moments and considering different plastic hinge lengths, and a simple steel frame structure. The beams are analyzed considering a pushover analysis, where rotations are incremented until reaching an ultimate rotation. For the first beam, equal moments are applied at each support, whereas in the second case, the moment applied at the left support is half of that applied to the right support. The steel element properties, including the parameters considered for the deterioration model, are presented in Table 1.

\section{Example 1}

A simply supported beam is analyzed considering equal moments and rotations applied at both ends. Fig. 7(a) shows the element end moment plotted against the element end rotation. A local response, corresponding to the rotation of a section at a distance $L_{p}$ from the support is also plotted against the end moment in Fig. 7(b). The rotation at a distance $L_{p}$ from the support, in the $\mathrm{CPH}$ model, must consider the rotation of the zero-length spring and the deformation of the elastic segment of length $L_{p}$.

In this figure, the plastic rotation of the $\mathrm{CPH}$ model is computed obtained by adding the rotation of the zero-length spring to the rotation of the elastic element over a length of $L_{p}$. The former is obtained by multiplying the curvature $(\chi)$ of the end section of the element by $L_{p}$.
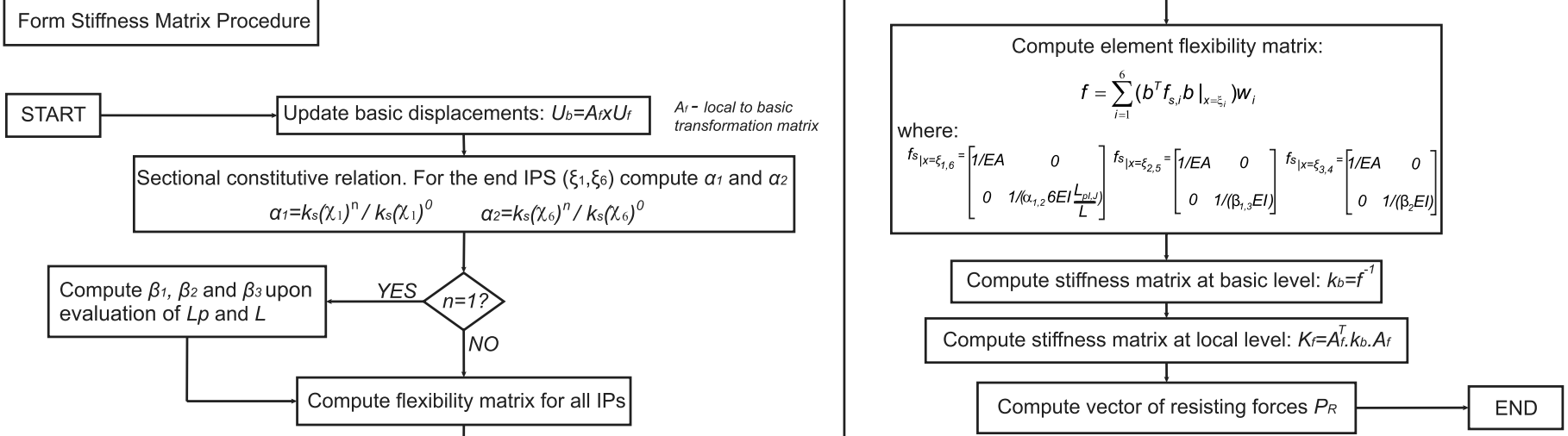

Fig. 6. Flowchart for computation of element stiffness matrix 

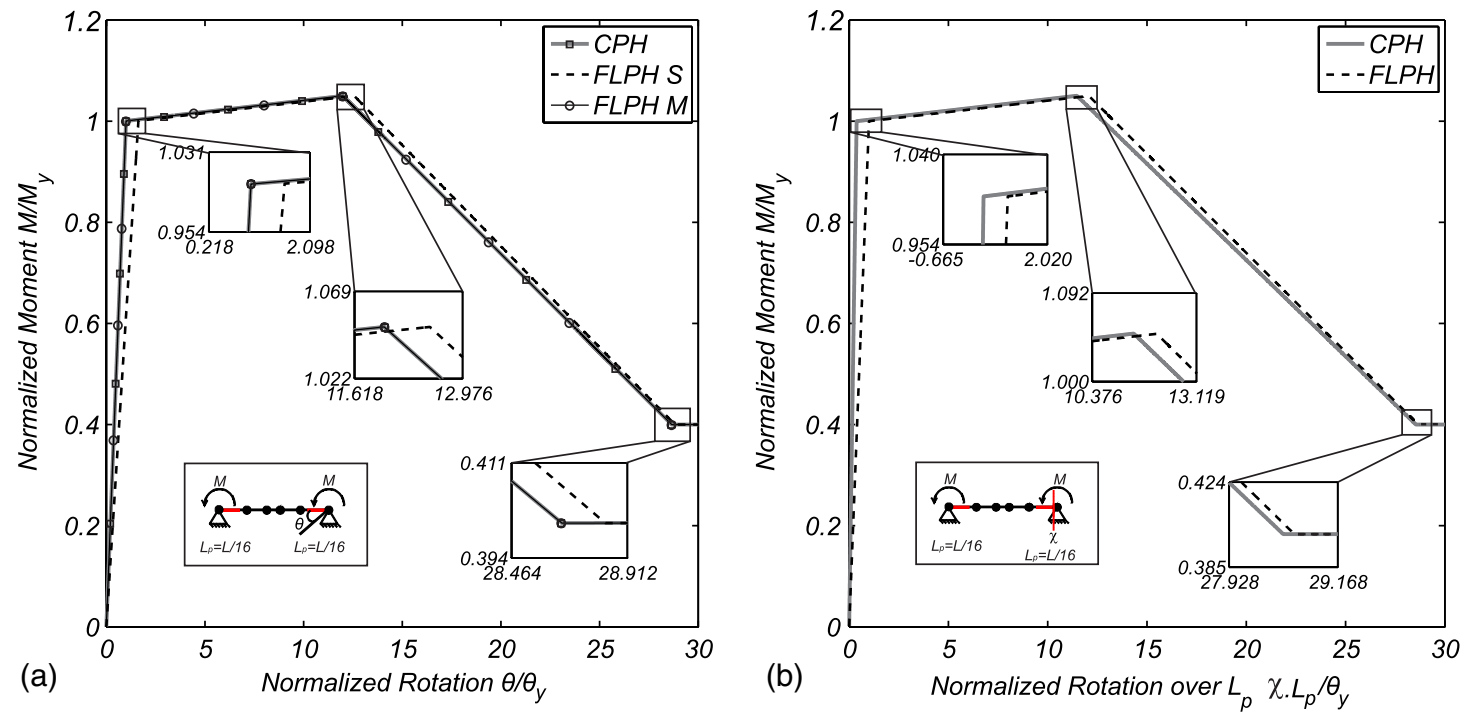

Fig. 7. Example 1 -basic system with equal moments at both ends and plastic hinge length $L_{p} / L=1 / 16$ : (a) global response; (b) local response

The CPH curve denotes the results obtained using a concentrated plastic hinge model, following the procedure employed by Lignos and Krawinkler (2013), and serves as a benchmark. Fig. 7(a) shows that end rotations obtained using the CPH model present an initial linear elastic response up to the yielding point, defined by the yielding moment-rotation pair $M_{y, \mathrm{CPH}}-\theta_{y, \mathrm{CPH}}$. Then, a linear hardening region connects the yielding point to the capping point $\left(M_{c, \mathrm{CPH}}-\theta_{c, \mathrm{CPH}}\right)$ and a linear softening region links the capping point to the residual moment-rotation point $\left(M_{r, \mathrm{CPH}}-\theta_{r, \mathrm{CPH}}\right)$, which is followed by a plastic region that extends to $\theta_{U}$. The second model considered (FLPH S) corresponds to the use of finite length plastic hinge elements, defining the moment-curvature relation through direct scaling of the rotation parameters $\left(\theta_{y}, \theta_{c}, \theta_{p c}, \theta_{r}\right.$, and $\left.\theta_{u}\right)$ by the plastic hinge length $L_{p}$ and no further calibration. The results show that this approach leads to erroneous results, as the elastic stiffness obtained is significantly lower than the target, and higher rotations are obtained in the softening branch. If the moment curvature is calibrated (curve FLPH M) using the proposed method, it is possible to reproduce the $\mathrm{CPH}$ behavior of the beam exactly for the entire analysis. Although the global response is in perfect agreement, Fig. 7(b) shows that the local response is different when the CPH or the FLPH $\mathrm{M}$ models are used. For the FLPH models, local response in Fig. 7(b) corresponds to the integration of the end section curvature $(\chi)$ over the plastic hinge length $L_{p}\left(\chi \times L_{p}\right)$. This result is equal for the FLPH $S$ and the FLPH M models because the end sections of both models are defined in a similar manner (only the interior sections are affected by the flexural modification parameters).

The results from this example highlight the the advantages of the calibration procedure proposed herein, namely showing that accurate results can be achieved for varying lengths of the plastic hinge and for cases considering softening.

\section{Example 2}

To show calibration for other moment gradients in the beam element, an identical beam to that from the previous example is analyzed considering the left moment equal to half of the right moment. As a result, the left end of the beam is always in the elastic range, and the beam does not deform in double curvature. However, as shown in Fig. 8, the results obtained for a plastic hinge length
$L_{p} / L=1 / 16$ are consistent with those obtained in Example 1. In fact, the results obtained with the scaled moment curvature relation without calibration (FLPH S) show significant errors from the elastic range, propagating over the entire range of analysis. When calibration is considered (FLPH M) the results are corrected and perfect agreement is found between CPH and FLPH M models. Fig. 9(a) shows the errors associated with the different models and different plastic hinge lengths. The errors are defined as the ratio between the computed slopes of the elastic, hardening, and softening branches, and the respective target moment-rotation defined in Lignos and Krawinkler (2011). The results show that: (1) the FLPH M calibration procedure provides accurate results when compared with the results obtained using $\mathrm{CPH}$ for the elastic, hardening and softening ranges of the response; and (2) the FLPH $\mathrm{S}$ procedure, where a scaled moment-curvature relation is used without further calibration, results in significant errors. It is worth noting that only for $L_{p} / L=1 / 6$ does the FLPH S model result in the exact moment-rotation at yielding and at the capping point, as previously shown by Scott and Ryan (2013). Fig. 9(b) shows the results obtained considering several plastic hinge lengths. The errors are computed by comparing the slopes of the elastic, hardening and softening branches of the two FLPH elements with the $\mathrm{CPH}$ model. Results show that the analysis presented for $L_{p} / L=1 / 16$ is valid for all values of the plastic hinge length. Furthermore, the results show that the proposed calibration procedure is applicable to different moment gradients besides anti-symmetric bending.

\section{Frame Structure}

A single-bay three-story frame with uniform stiffness and strength over its height (Fig. 10) is used to illustrate the application of the calibration procedure described above. A dead load of $889.6 \mathrm{kN}$ is applied to each story, giving a total structure weight $W$ of $2,669 \mathrm{kN}$. The flexural stiffness EI is identical for beams and columns with values given in Table 1. Plastic hinges form at beam ends and at base columns. The other columns are assumed to remain elastic. Pushover analyses of the frame are conducted in the OpenSees framework (McKenna et al. 2000) using a P-Delta geometric transformation for the columns. Results obtained with model FLPH M are compared with results obtained using the $\mathrm{CPH}$ models. It is 

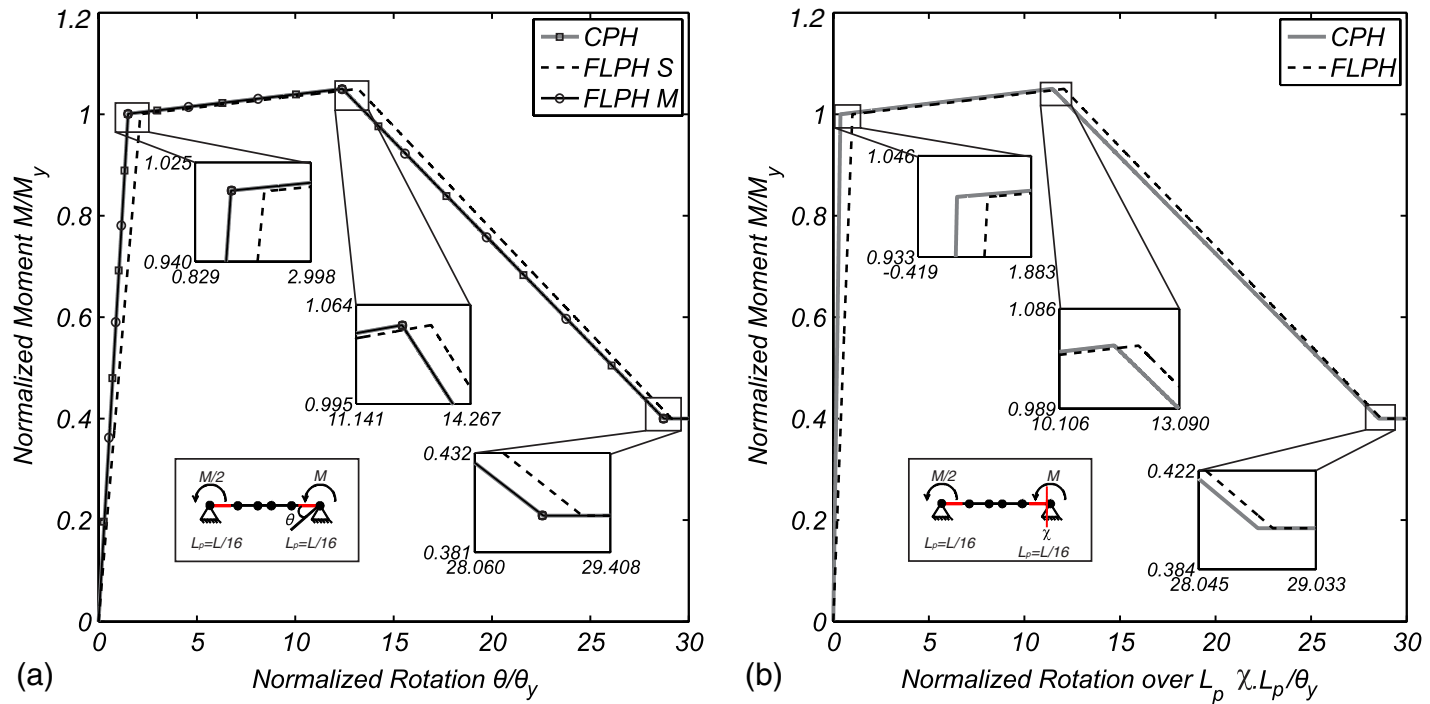

Fig. 8. Example 2-basic system with different moments at both ends and plastic hinge length $L_{p} / L=1 / 16$ : (a) global response; (b) local response
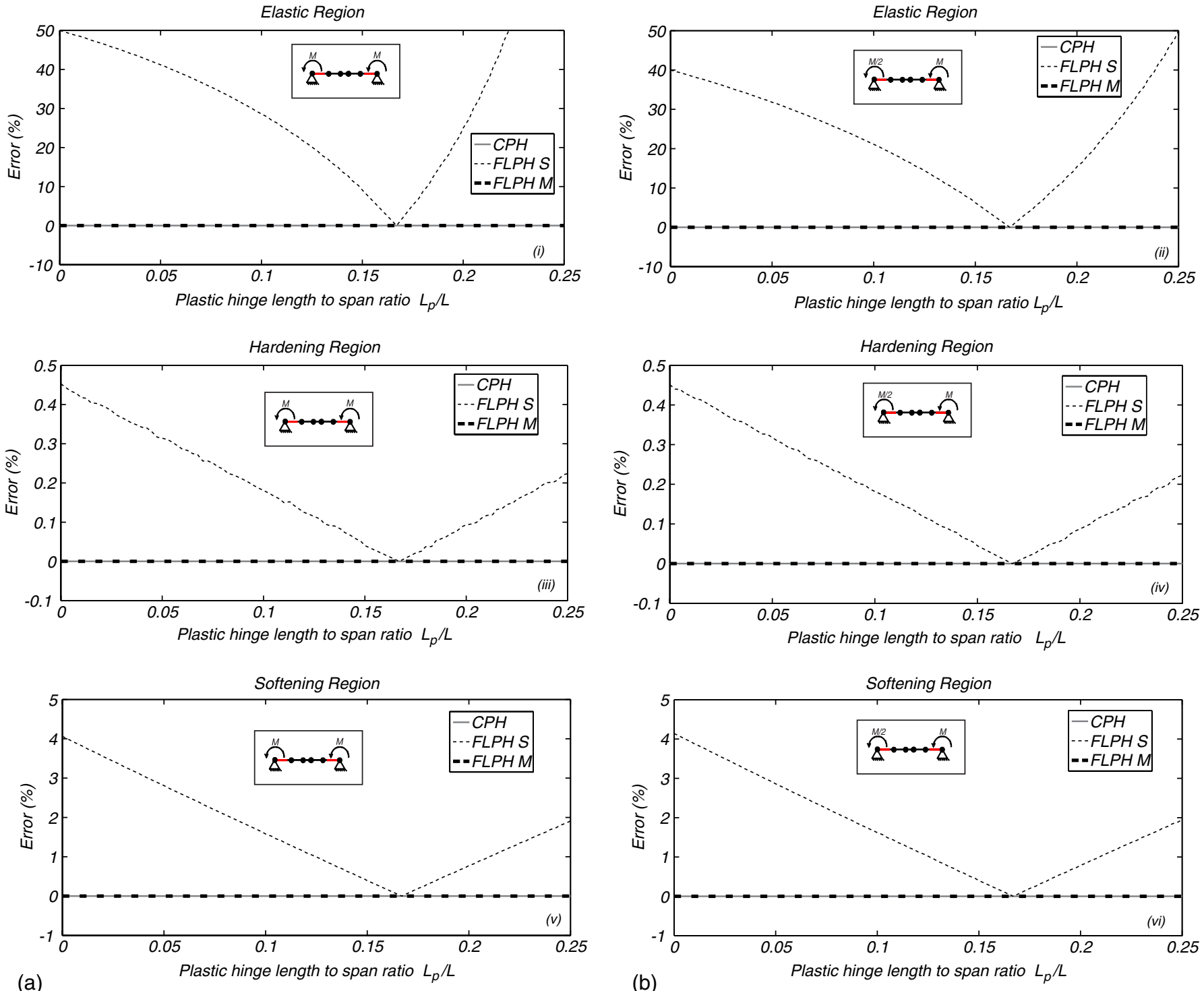

Fig. 9. Errors in the slopes of the elastic, hardening and softening regions for the CPH, FLPH S and FLPH M models during a monotonic analysis for (a) Example 1; (b) Example 2 


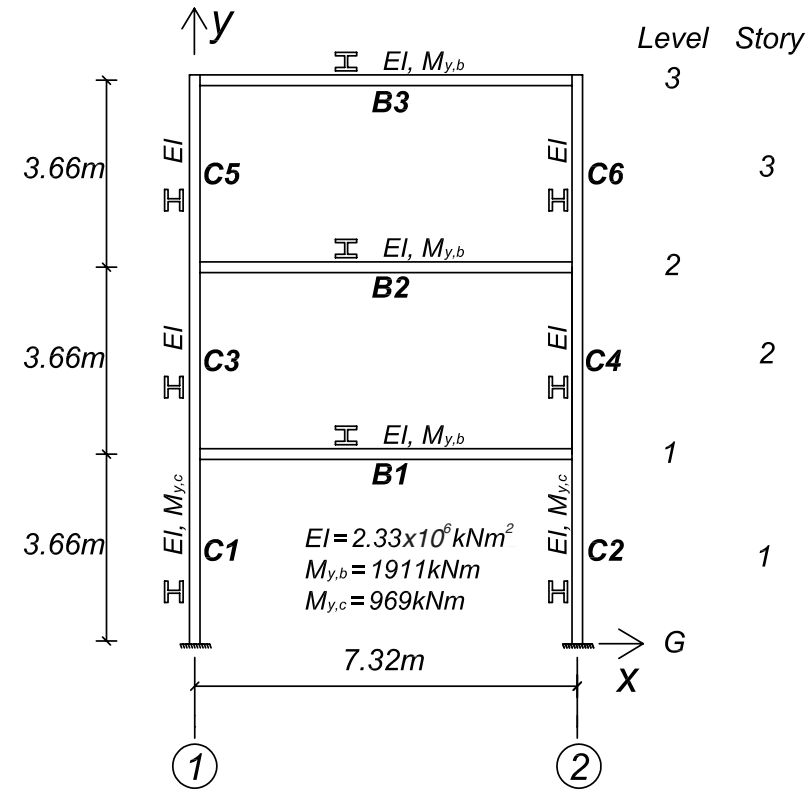

Fig. 10. Steel moment frame

worth noting that in steel W-shape beams with shape factors ( $k=M_{p} / M_{y}$ ) of approximately 1.12 , the plastic hinge length is taken as $10 \%$ of the distance between the point of maximum moment and the inflection point (Bruneau et al. 1998). This value is slightly larger, approximately $12.5 \%$, at the center of beams that are subjected to distributed loads. Thus, for members in a state of antisymmetric double curvature, it is suggested that a plastic hinge length between $L / 20$ and $L / 16$ be used.

Fig. 11(a) shows the normalized base shear $(V / W)$ versus roof drift ratio for the three models and Fig. 11(b) illustrates the beam moment-rotation response. The results obtained for this frame show that the conclusions drawn for the two previous examples hold, namely FLPH S should not be used as a procedure for converting from empirical moment-rotation relations to moment-curvature relations when FLPH elements are used, and FLPH M is an adequate procedure that produces objective results without computationally expensive iterative/updating procedures.

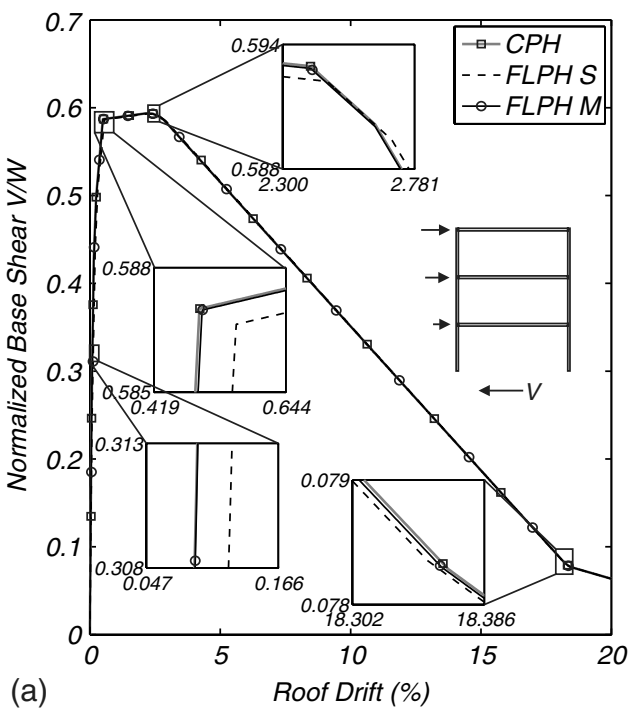

\section{Conclusions}

The present work proposes a calibration procedure that allows the use of FLPH force-based beam-column elements for steel moment frames that exhibit softening response at the section and element levels. The use of scaled but uncalibrated moment-curvature relationships in FLPH elements leads to significant errors in both local and global responses and is therefore not adequate for structural analysis. The new calibration procedure is performed at the element level through the introduction of section flexural stiffness modification parameters $(\beta)$, which are computed at the beginning of the analysis as a function of the user defined plastic hinge lengths. The modification parameters are obtained by equating element flexural coefficients of the flexibility matrix and target flexibility matrix, where the latter is given by the user-defined moment-rotation relation and is computed in this work using a CPH model. Nonlinear static analyses of two simply supported beams and pushover analysis of a steel moment-resisting frame were performed considering different plastic hinge lengths. The results illustrate that the exact linear elastic stiffness can be recovered for linear problems while ensuring objective response after the onset of deterioration. The cases studied and error analysis based on analytical expressions show that the calibration procedure is valid for any moment gradient. Even though the proposed calibration procedure has only been validated for multilinear moment-rotation relationships, it is, in principle, possible to use it with other constitutive laws, where moment-rotation can be related to moment-curvature by a user-defined plastic hinge length. The calibration procedure was validated at the section level for bending moments and rotations only, but similar approaches may be used for cases in which the interaction between bending and axial deformations is considered. The accuracy and stability of the proposed calibration procedure remains to be studied for nonlinear dynamic time-history analysis of steel moment frame buildings.

\section{Appendix I. Error in the Model Elastic Stiffness Associated with the CPH Springs Elastic Stiffness Amplification Factor}

In $\mathrm{CPH}$ models, the elastic stiffness amplification factor $(n)$ should be chosen carefully because an excessively large value would pose numerical problems, whereas a value that is not sufficiently large

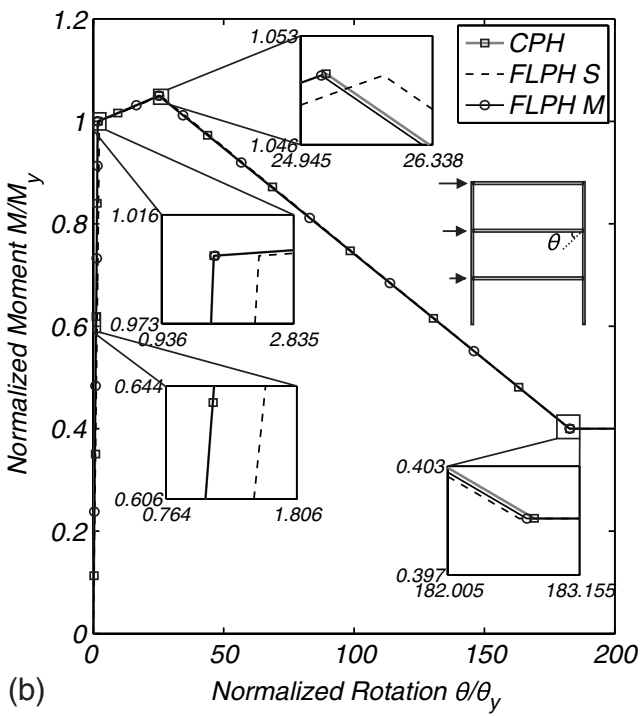

Fig. 11. Example three-story frame used to demonstrate the proposed calibration procedures: (a) pushover curve; (b) beam response 
will lead to erroneous results in the elastic range. In this Appendix, elastic stiffness errors associated with values of $n<1000$ are computed.

Considering that each member can be represented by two end rotational springs and an elastic frame element in series, the flexibilities of the springs and the frame element in a CPH element are additive. Using the tangent stiffnesses, $k_{T I}$ and $k_{T J}$, of each rotational spring, the member flexibility is

$$
f_{b}=\left[\begin{array}{cc}
1 / k_{T I} & 0 \\
0 & 0
\end{array}\right]+\frac{L}{6 E I_{\bmod }} \times\left[\begin{array}{cc}
2 & -1 \\
-1 & 2
\end{array}\right]+\left[\begin{array}{cc}
0 & 0 \\
0 & 1 / k_{T J}
\end{array}\right]
$$

To recover the correct linear-elastic solution for the entire $\mathrm{CPH}$ model, the end rotational springs need to be approximated as rigidplastic with an initial stiffness that is large, but not so large to pose numerical instability. This is akin to the selection of large penalty values when enforcing multi-point constraints in a structural model (Cook et al. 2001). The ratio of flexibility coefficient $f_{b}(1,1)$ to the exact linear-elastic solution $L /(3 E I)$ is plotted in Fig. 12 versus the elastic stiffness amplification factor, which scales the characteristic element stiffness $6 E I / L\left(k_{I}=n \times 6 E I_{\text {mod }} / L\right)$.

As shown in Fig. 12, the ratio between the elastic stiffness recovered using different $n$ values for the CPH model and the target elastic stiffness $(L / 3 E I)$ varies from 0.9545 (4.55\% error) for $n=10$ to 0.9995 ( $0.05 \%$ error) for $n=1,000$. Thus, to recover the elastic solution with negligible errors, it is suggested that a value of $n=1,000$ be used.

Although the suggested value of $n \geq 1,000$ allows for recovery of the elastic stiffness, several authors have highlighted that there is an increased likelihood of nonconvergence of nonlinear timehistory response analyses if such a large value of $n$ is used. For this reason, Zareian and Medina (2010) have suggested the use of $n=10$. However, the use of such a low value of $n$ can lead to underestimating the elastic flexibility of the elements up to $4.55 \%$, which could lead to approximately $13 \%$ error in natural frequencies of vibration.

\section{Appendix II. Computation of the Section Flexural Stiffness Modification Parameters}

The following code was implemented in the wxMaxima software (Souza et al. 2003).

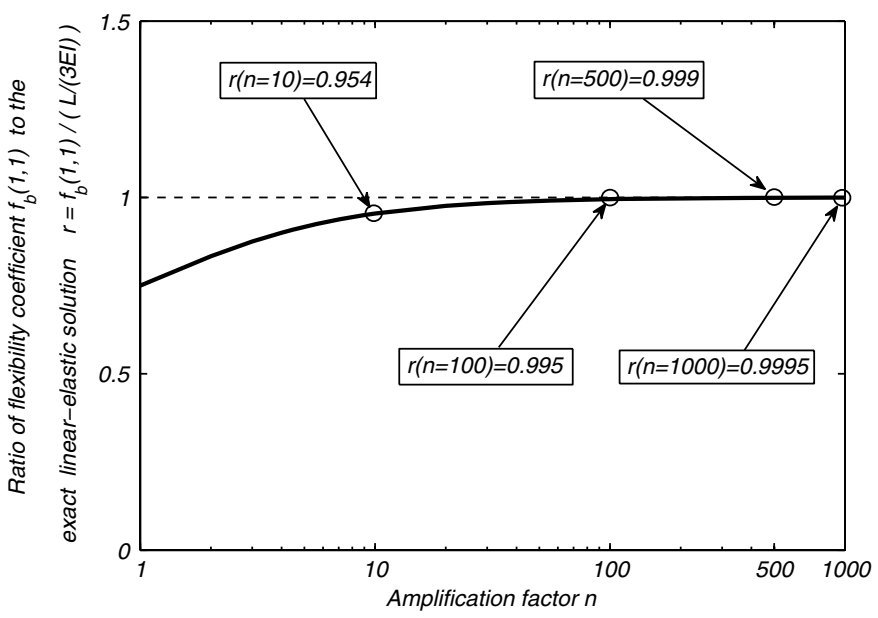

Fig. 12. Computed elastic flexibility coefficient of concentrated plasticity model versus rigid-plastic approximation of end springs
- Unknowns

- Input data

$$
\beta_{1}, \beta_{2}, \beta_{3}
$$

$$
\begin{aligned}
& y:\left[0,8 / 3 \times L_{p I}, L-8 / 3 \times L_{p J}, L\right] ; \\
& w:\left[L_{p I}, 3 \times L_{p I}, 3 \times L_{p J}, L_{p J}\right] ; \\
& m p:\left[\alpha_{1} \times 6 \times L_{p I} / L, \beta_{1}, \beta_{3}, \alpha_{2} \times 6 \times L_{p J} / L\right] ;
\end{aligned}
$$

- Computation of the element flexibility matrix (flexural terms only)

$$
f_{1}: \operatorname{matrix}([0,0],[0,0]) ;
$$

- Plastic hinges integration points

for $i: 1$ to 4 do

$$
\begin{aligned}
& \left(f_{1}: f_{1}+\operatorname{transpose}(\operatorname{matrix}([0,0],[y[i] / L-1, y[i] / L])) .\right. \\
& \operatorname{matrix}([0,0],[y[i] / L-1, y[i] / L]) \times w[i]) \\
& \times(1 /(m p[i] * E I)) ;
\end{aligned}
$$

- Interior region

$f_{1}: f_{1}+$ integrate $(\operatorname{transpose}(\operatorname{matrix}([0,0],[x / L-1, x / L]))$.

$\operatorname{matrix}([0,0],[x / L-1, x / L]) \times\left(1 /\left(\beta_{2} \times E I\right)\right)$,

$\left.x, 4 \times L_{p I}, L-4 \times L_{p J}\right)$;

- Computation of the target flexibility matrix using a CPH model (flexural terms only)

- $\mathrm{CPH}$ model parameters

$$
\begin{aligned}
& E I_{\text {mod }}: E I \times(n+1) / n ; \\
& K_{\text {spring }}: n \times 6 \times E I_{\text {mod }} / L ; \\
& m p_{2}:\left[\left(\alpha_{1}\right) /\left(1+n \times\left(1-\alpha_{1}\right)\right),\right. \\
& \left.\left(\alpha_{2}\right) /\left(1+n \times\left(1-\alpha_{2}\right)\right)\right] ;
\end{aligned}
$$

- Model flexibility matrix

$f_{2}: \operatorname{matrix}\left(\left[1 /\left(m p_{2}[1] \times k_{\text {spring }}\right), 0\right],\left[0,1 /\left(m p_{2}[2] \times k_{\text {spring }}\right)\right]\right)$; $f_{2}: f_{2}+$ integrate $(\operatorname{transpose}(\operatorname{matrix}([0,0],[x / L-1, x / L]))$. $\left.\operatorname{matrix}([0,0],[x / L-1, x / L]) \times\left(1 /\left(E I_{\text {mod }}\right)\right), x, 0, L\right)$;

- Solve the system of equations for obtaining unknowns

$$
\begin{aligned}
& e q_{1}: f_{1}[1,1]=f_{2}[1,1] \\
& e q_{2}: f_{1}[1,2]=f_{2}[1,2] \\
& e q_{3}: f_{1}[2,2]=f_{2}[2,2] \\
& \text { sol:solve }\left(\left[e q_{1}, e q_{2}, e q_{3}\right],\left[\beta_{1}, \beta_{2}, \beta_{3}\right]\right)
\end{aligned}
$$

- Although the previous step already gives a solution for the problem, it is useful to obtain the solution without dependency on $n$. Thus, the solution, sol, is evaluated when $n$ tends to infinity

$$
\operatorname{limit}(\operatorname{sol}, n, \inf ) \text {; }
$$

\section{Acknowledgments}

In the development of this research work, the first and fourth authors would like to acknowledge the support of the Portuguese Science and Technology Foundation through the program SFRH/ BD/77722/2011 and UNIC Research Center at the Universidade 
Nova de Lisboa. The support of the School of Civil and Construction Engineering at Oregon State University to the second and third authors is gratefully acknowledged. The opinions and conclusions presented in this paper are those of the authors and do not necessarily reflect the views of the sponsoring organizations.

\section{References}

Addessi, D., and Ciampi, V. (2007). "A regularized force-based beam element with a damage plastic section constitutive law." Int. J. Numer. Methods Eng., 70(5), 610-629.

Alemdar, B., and White, D. (2005). "Displacement, flexibility, and mixed beam-column finite element formulations for distributed plasticity analysis." J. Struct. Eng., 10.1061/(ASCE)0733-9445(2005)131: 12(1811), 1811-1819.

Berry, M., Lehman, D., and Lowes, L. (2008). "Lumped-plasticity models for performance simulation of bridge columns." ACI Struct. J., 105(3), 270-279.

Bruneau, F., Uang, C.-M., and Whittaker, A. (1998). Ductile design of steel structures, McGraw-Hill, New York.

Calabrese, A., Almeida, J., and Pinho, R. (2010). "Numerical issues in distributed inelasticity modeling of rc frame elements for seismic analysis." J. Earthquake Eng., 14(S1), 38-68.

Clough, R., Benuska, K., and Wilson, E. (1965). "Inelastic earthquake response of tall buildings." 3rd World Conf. on Earthquake Engineering, Vol. 2, Wellington, New Zealand National Committee on Earthquake Engineering, 68-81.

Coleman, J., and Spacone, E. (2001). "Localization issues in force-based frame elements." J. Struct. Eng., 10.1061/(ASCE)0733-9445(2001) 127:11(1257), 1257-1265.

Cook, R. D., Malkus, D. S., Plesha, M. E., and Witt, R. J. (2001). Concepts and applications of finite element analysis, 4th Ed., Wiley, New York.

De Borst, R., Crisfield, M., Remmers, J., and Verhoosel, C. (2012). Nonlinear finite element analysis of solids and structures, 2nd Ed., Wiley, New York.

El-Tawil, S., and Deierlein, G. G. (1998). "Stress-resultant plasticity for frame structures." J. Eng. Mech., 10.1061/(ASCE)0733-9399(1998) 124:12(1360), 1360-1370.

Foliente, G. (1995). "Hysteresis modeling of wood joints and structural systems." J. Struct. Eng., 10.1061/(ASCE)0733-9445(1995)121: 6(1013), 1013-1022.

Giberson, M. (1969). "Two nonlinear beams with definitions of ductility." J. Struct. Div., 95(2), 137-157.

Gupta, A., and Krawinkler, H. (1999). "Seismic demands for performance evaluation of steel moment resisting frame structures." Rep. no. 132, John A. Blume Earthquake Engineering Center, Stanford Univ., Stanford, CA.

Haselton, C., and Deierlein, G. (2007). "Assessing seismic collapse safety of modern reinforced concrete frame buildings." Rep. no. 156, John A. Blume Earthquake Engineering Center, Stanford Univ., Stanford, CA.

Ibarra, L. F., and Krawinkler, H. (2005). "Global collapse of frame structures under seismic excitations." Rep. no. 152, John A. Blume Earthquake Engineering Research Center, Dept. of Civil Engineering, Stanford Univ., Stanford, CA.
Kang, Y. (1977). "Nonlinear geometric, material and time dependent analysis of reinforced and prestressed concrete frames." UC-SESM Rep. No. 77-1, Univ. of California, Berkeley, CA.

Lignos, D., and Krawinkler, H. (2013). "Development and utilization of structural component databases for performance-based earthquake engineering." J. Struct. Eng., 10.1061/(ASCE)ST.1943-541X.0000646, 1382-1394.

Lignos, D. G., and Krawinkler, H. (2011). "Deterioration modeling of steel components in support of collapse prediction of steel moment frames under earthquake loading." J. Struct. Eng., 10.1061/(ASCE)ST.1943541X.0000376, 1291-1302.

McKenna, F., Fenves, G., and Scott, M. (2000). Open system for earthquake engineering simulation, Univ. of California, Berkeley, CA.

Medina, R., and Krawinkler, H. (2005). "Evaluation of drift demands for the seismic performance assessment of frames." J. Struct. Eng., 10.1061/(ASCE)0733-9445(2005)131:7(1003), 1003-1013.

Neuenhofer, A., and Filippou, F. (1997). "Evaluation of nonlinear frame finite-element models.” J. Struct. Eng., 10.1061/(ASCE)0733-9445 (1997)123:7(958), 958-966.

PEER/ATC. (2010). "Modeling and acceptance criteria for seismic design and analysis of tall buildings." Rep. No. 72-1, ATC-Applied Technology Council, Redwood City, CA.

Pincheira, J., Dotiwala, F., and D'Souza, J. (1999). "Seismic analysis of older reinforced concrete columns." Earthquake Spectra, 15(2), $245-272$

Roufaiel, M., and Meyer, C. (1987). "Analytical modeling of hysteretic behavior of r/c frames." J. Struct. Eng., 10.1061/(ASCE)0733-9445 (1987)113:3(429), 429-444.

Scott, M. H., and Fenves, G. L. (2006). "Plastic hinge integration methods for force-based beam-column elements." J. Struct. Eng., 10.1061/ (ASCE)0733-9445(2006)132:2(244), 244-252.

Scott, M. H., and Fenves, G. L. (2010). "Krylov subspace accelerated newton algorithm: Application to dynamic progressive collapse simulation of frames." J. Struct. Eng., 10.1061/(ASCE)ST.1943-541X.0000143, 473-480.

Scott, M. H., and Ryan, K. L. (2013). "Moment-rotation behavior of forcebased plastic hinge elements." Earthquake Spectra, 29(2), 597-607.

Sivaselvan, M., and Reinhorn, A. (2000). "Hysteretic models for deteriorating inelastic structures.” J. Eng. Mech., 10.1061/(ASCE)0733-9399 (2000)126:6(633), 633-640.

Souza, P. N., Fateman, R., Moses, J., and Yapp, C. (2003). The maxima book, 〈http://maxima.sourceforge.net〉 (Jan. 2013).

Spacone, E., and Filippou, F. (1992). A beam model for damage analysis of reinforced concrete structures under seismic loads, Dept. of Civil Engineering, Univ. of California, Berkeley, CA.

Spacone, E., Filippou, F., and Taucer, F. (1996). "Fibre beam-column model for nonlinear analysis of R/C frames: Part I. Formulation." Earthquake Eng. Struct. Dyn., 25(7), 711-726.

Takeda, T., Sozen, M., and Nielson, N. (1970). "Reinforced concrete response to simulated earthquakes." J. Struct. Div., 96(12), 2557-2573.

Taylor, R. (1977). "The nonlinear seismic response of tall shear wall structures." Ph.D. thesis, Dept. of Civil Engineering, Univ. of Canterbury, Christchurch, New Zealand, 207.

Zareian, F., and Medina, R. A. (2010). "A practical method for proper modeling of structural damping in inelastic plane structural systems." Comput. Struct., 88(1-2), 45-53. 